\title{
ANALYSIS OF UNIFORMITY OF THE DISTRIBUTION OF REINFORCING PHASE IN CU/SiC COMPOSITE MATERIALS USING $\mu$ CT METHODS
}

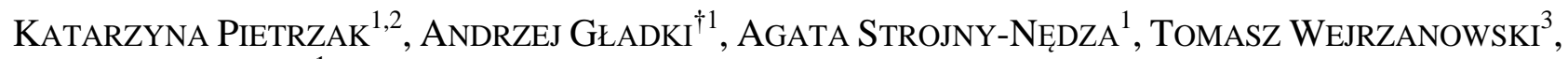 \\ KAMIL KASZYCA ${ }^{\square, 1}$ \\ ${ }^{1}$ Lukasiewicz Research Network - Institute of Microelectronics and Photonics, Poland; ${ }^{2}$ Institute of \\ Fundamental Technological Research of the Polish Academy of Sciences, Poland; ${ }^{3}$ Warsaw University of \\ Technology, Faculty of Materials Science and Engineering, Poland \\ e-mail: Katarzyna.Pietrzak@imif.lukasiewicz.gov.pl, Gladki.A@gmail.com, \\ Agata.Strojny@imif.lukasiewicz.gov.pl, Tomasz.Wejrzanowski@pw.edu.pl, \\ Kamil.Kaszyca@imif.lukasiewicz.gov.pl \\ (Received February 14, 2018; revised November 24, 2020; accepted April 2, 2021)
}

\begin{abstract}
Tomography allows embedding of one space in another, especially $\mathcal{R}^{2} \rightarrow \mathcal{R}^{3}$, and observation of the nature of the volumetric internal composite structure. Now, not only a simple interpretation is expected of geometry defined via single thresholds of structures. The binary segmentation used for numerical structure analysis requires more detailed presentation. This paper shows an example of image analysis techniques applied to study the homogeneity of two-phase material. Using tomography analysis, the results of the homogeneity of the SiC particles with 10vol.\%, 20vol.\%, 30vol.\%, 40vol.\% volumetric bulk density of $\mathrm{Cu} / \mathrm{SiC}$ composites are presented. Finally, for two independent coordinate systems, the distribution of $\mathrm{SiC}$ particle masses and their total moments of inertia were determined. The results confirmed that for well-mixed composite powders the homogeneity of the reinforcing phase is expected in samples with a $\mathrm{SiC}$ volume near 30vol.\%. In this case, segregation by translation and rotation of SiC particles in the matrix, during the sintering process is restricted.
\end{abstract}

Keywords: $\mathrm{Cu} / \mathrm{SiC}$ composite materials, image analysis, isotropy, uniformity.

\section{INTRODUCTION}

Copper, with its good thermal and electrical conductivity, corrosion resistance and high melting point, is commonly used in the following industries: energy, electronics, automotive and aviation. However, its relatively low mechanical strength, both at low and high temperatures, limits the possibility of using pure copper (Campbell F.C., 2010). This is why various forms of reinforcing phases are used for the copper matrix, i.e. particles, flakes, fibers or whiskers (Jarzabek D. et al., 2016; Pietrzak K. et al., 2016; Iguchi M. et al., 1982; Yoshida K. et al., 2004 Weber L. et al., 2007). One of such phases is silicon carbide (SiC) which makes the composite material $\mathrm{Cu} / \mathrm{SiC}$ similar to pure copper, but more mechanically durable. The addition of $\mathrm{SiC}$ as the reinforcement reduces also its coefficient of linear expansion (Singh H. et al., 2015; Chmielewski M. et al., 2017; Zhan Y. et al., 2003). It most cases isotropic mechanical strength and linear expansion both are expected (Besharati M.K. et al., 2011; Barmouz M. et al., 2014; Srinivasan C. et al.,
2015). Gradient or laminated materials are an exception. Fabrication of isotropic structures with the use of powder metallurgy in composites with a molecular reinforcing phase requires proper selection of shapes and sizes of powder particles as early as in the mixing process (Gan K. et al., 2008; Zaman M. et al., 2012). Sintering a mixture of $\mathrm{Cu}$ and $\mathrm{SiC}$ powders sometimes requires certain modifications. Due to the interaction between $\mathrm{Cu}$ and $\mathrm{SiC}$, the surface of $\mathrm{SiC}$ grains can be modified by coating with e.g. molybdenum (Schubert Th., et al., 2007) or tungsten (Chmielewski M. et al., 2017). Quantitative structural analysis of composite materials, including the measurements of phase compositions, the size of grains and molecules, their surface, volume, shape, uniformity and isotropy (Gawdzińska K. et al., 2010) are conducted via two methods. The first method uses all the methodological gains of the so-called Quantitative Metallography (QM). QM methods make it possible to estimate various geometric parameters of structures, based on the analysis of 2D images (Underwood E.E. 1970; DeHoff R.T. et al., 1961; Głowacz E. et al., 
2008; Xu Y.H. et al., 2003; Wejrzanowski T. et al., 2010; Wejrzanowski T. et al., 2008). The second group of methods uses computer tomography (CT) at various resolutions in order to visualize structure and perform quantitative analysis in $3 \mathrm{D}$ space. Thanks to rapid development of computers X-ray tomography ( $\mu \mathrm{CT}$ ) and 3D image analysis is a valuable tool for the analysis of materials at various length scales. Applications, advantages and limitations of CT methods have been extensively reviewed in the article "Quantitative X-ray tomography" (Maire E. et al., 2014). The paper shows an example of the use of algorithms for particles, represented by the images of their binary masks. After imaging in 3D space, the centers of mass of the particular SiC particles, as well as their volumes, were determined. These parameters were used for the analysis of isotropy and uniformity of distribution of $\mathrm{SiC}$ reinforcing phase in $\mathrm{Cu}-\mathrm{SiC}$ composites with the volume fraction of $\mathrm{SiC}$ from 1040\%. $\mathrm{Cu} / \mathrm{SiC}$ composites were manufactured using the powder metallurgy method. The copper powder (NewMet Koch) was used, as well as the Sika SaintGobain silicon carbide. Fig. 1 presents the SEM image of the $\mathrm{Cu}-\mathrm{SiC}$ powder mixture, the shape factors of projections of powder particles on a measuring surface, as well as the distributions of values of Feret's diameters.

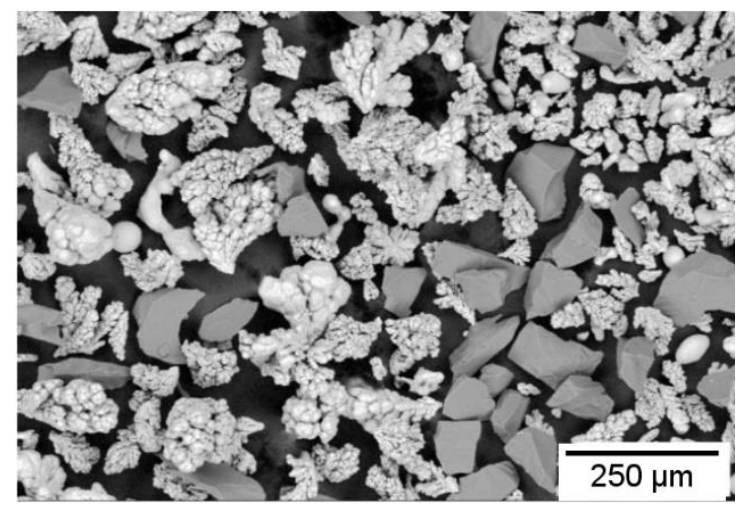

a)

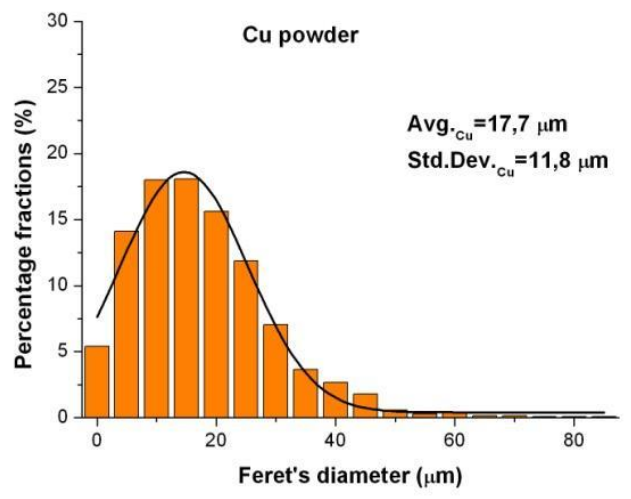

c)

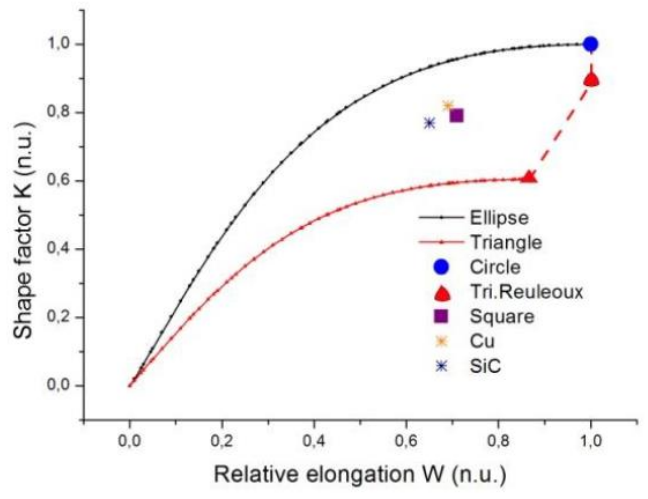

b)

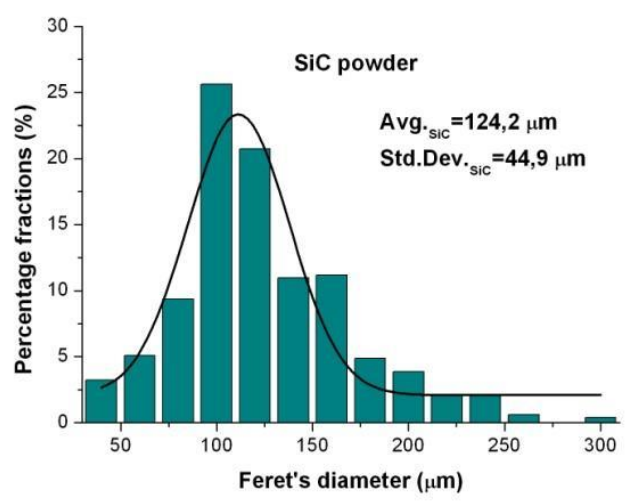

d)

Fig. 1. a) SEM image of Cu (light) and SiC (gray) particles; b) Shape parameters in 2D space of convex shapes for particles projections; c) Feret's diameters distribution of Cu powder particles; d) Feret's diameters distribution of SiC powder particles.

The granulometric analysis of powders based on optical microscopy images with the resolution of 2.1 $\mu \mathrm{m} /$ pixel was conducted using Vision PE by CLEMEX. For the shape analysis, modified KS 300 Zeiss procedure libraries were used. In the direct measurements - Clemex - the average Feret's diameter was determined, from the projections of the image of a single 2D particle in coordinate systems rotated in a range of angles $0-157.5^{\circ}$ with the step of $22.5^{\circ}$. The shape factor of particles was determined from their binary masks consisting of convex polygons - KS 300 procedure. Convex areas of polygons $\mathrm{A}_{\mathrm{C}}$ were 
measured, as well as the corresponding convex perimeters $P_{C}$ and both Feret's diameters $d_{\min }$ and $d_{\max }$. The following equation were used to calculate shape factors: $=4 \pi \frac{A_{c}}{P_{c}^{2}} ; K \in(0 ; 1]$;

as well as $W=\frac{d_{\min }^{F}}{d_{\max }^{F}} ; W \in(0 ; 1]$,

where values create the space of flat convex shapes, limited with strings of ellipses, triangles and figures with constant width - circles and Reuleaux triangles - Fig. 1b. Powders used in this study consisted with particles with the average Feret's diameter: $\bar{d}_{C u}=17.7 \mu m$ and ${\overline{d^{F}}}_{\text {SiC }}=124.2 \mu \mathrm{m}$. The shape factors of both types of powder particles were approximately square $\left[\begin{array}{l}K=0.71 \\ W=0.79\end{array}\right]$ and were respectively:

$$
\left[\begin{array}{l}
K_{S i C}=0.77 \\
W_{S i C}=0.65
\end{array}\right] \text { and }\left[\begin{array}{l}
K_{C u}=0.82 \\
W_{C u}=0.69
\end{array}\right]
$$

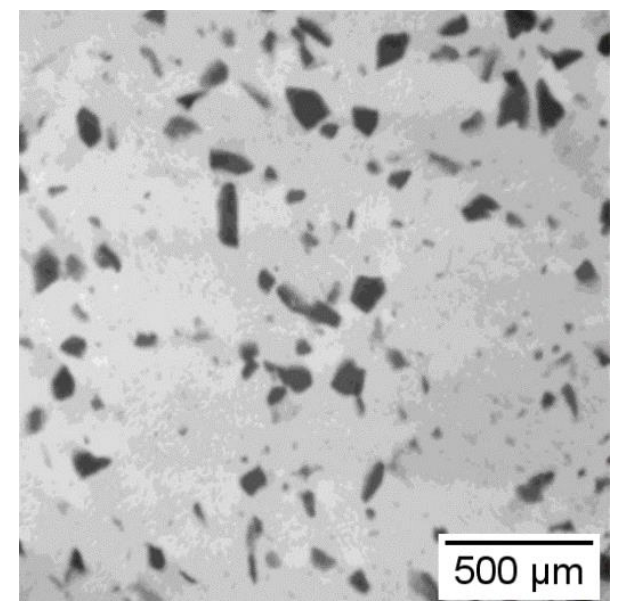

a) $\mathrm{Cu}-10 \%$ vol. $\mathrm{SiC}$

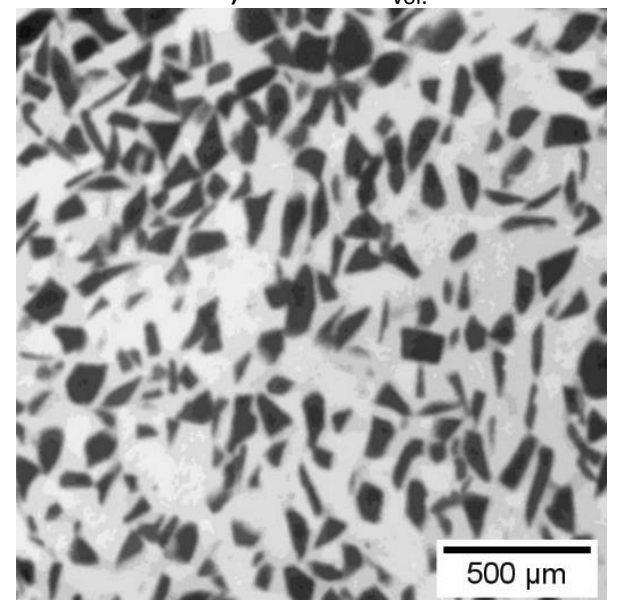

c) $\mathrm{Cu}-30 \%{ }_{\text {vol. }} \mathrm{SiC}$
Particles of $\mathrm{Cu}$ and $\mathrm{SiC}$ powders had similar shapes. The difference between both powders particle size was in the range of one order of magnitude. The range of Feret's diameters of copper powder was a subset of the range of $\mathrm{SiC}$ diameter ranges. Due to the similarity in shapes and sizes of particles of both powders, the probability of their uniform mixing was very high. Powders were mixed in a Fritsch planetary mill, and the composite material was sintered using the SPS method. Following composites were manufactured:

$$
\text { Cu }-x \%_{\text {vol. }} \text { SiC }, x=\{10,20,30,40\}
$$

The central areas $(2 \times 2 \times 2 \mathrm{~mm})$ of the samples were analyzed with an XRADIA XCT-400 X-ray microtomography $(\mu \mathrm{CT})$. The source of radiation was an X-ray lamp, operating at $150 \mathrm{kV}$ with the current of $64 \mu \mathrm{A}$. From every sample 1000 projections were obtained in the angular position $0 \div 180^{\circ}$. The linear scanning resolution was $2 \mu \mathrm{m}$.

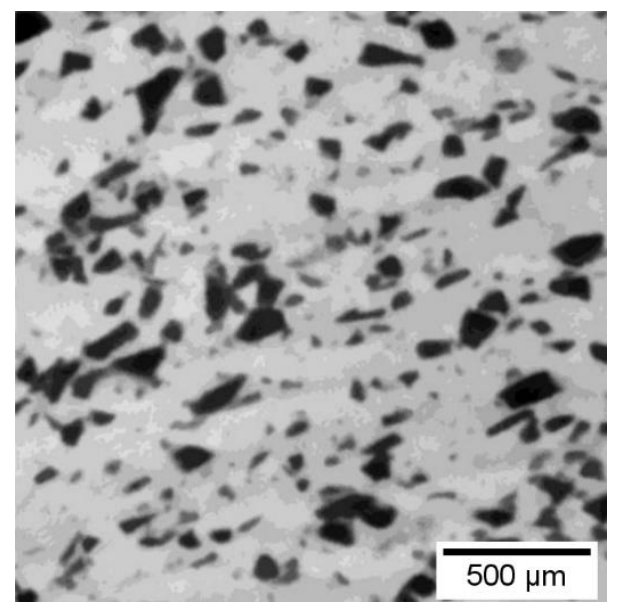

b) $\mathrm{Cu}-20 \%$ vol. $\mathrm{SiC}$

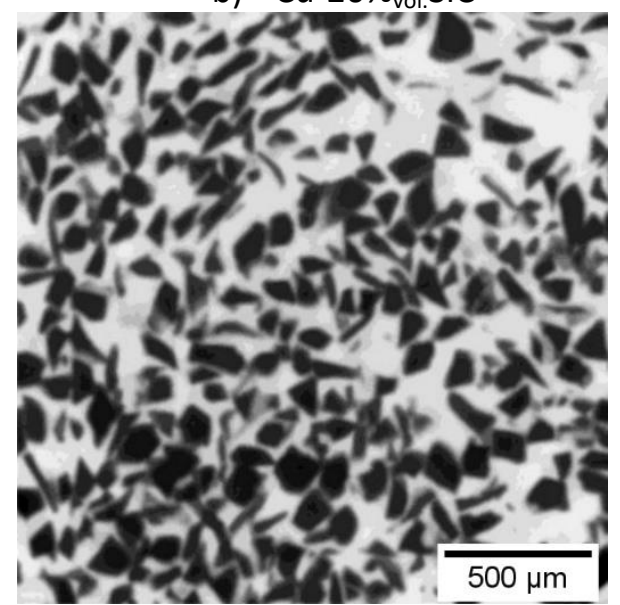

d) $\mathrm{Cu}-40 \%$ vol. $\mathrm{SiC}$

Fig. 2. $\mu \mathrm{CT}$ single images of the $\mathrm{SiC/Cu}$ composite with various $\mathrm{SiC}$ volume fraction. 
In Fig. 2 examples of the single images from the set of tomographic data are presented for materials with varying volume fraction of reinforcing phase. One of the basic parameter which might be calculated is the volume fraction of $\mathrm{SiC}$ phase, which is determined by summing up the number of pixels/voxels inside objects identified as SiC. More complicated analysis is related with isotropy and uniformity of distribution of $\mathrm{SiC}$ phase within the $\mathrm{Cu}$ matrix. The analysis of isotropy and uniformity follows a certain convention (Figs. 3, 4). Uniformity results from isotropy, not the other way around. Isotropy depends on the choice of a coordinate system (Fig. 4b). In order to study isotropy and uniformity of $\mathrm{SiC}$ particles in a $\mathrm{Cu}$ matrix, the individual position of each particles and their volume (mass) have to be calculated.

If the space is isotropic around observer $X$, the densities at 1, 2, and 3 are equal. Drawing spheres of different radii around observer $Y$, it is seen that the region within the spherical shell around $\mathrm{Y}$ has to be homogeneous. Credit: J.A. Peacock 1999, Cosmological Physics, Cambridge University Press

The separation of particles in each of the 4000 photos was conducted via analyzing binary masks overlaid on particle images. Separation was conducted using the procedures of the Clemex Vision PE program.

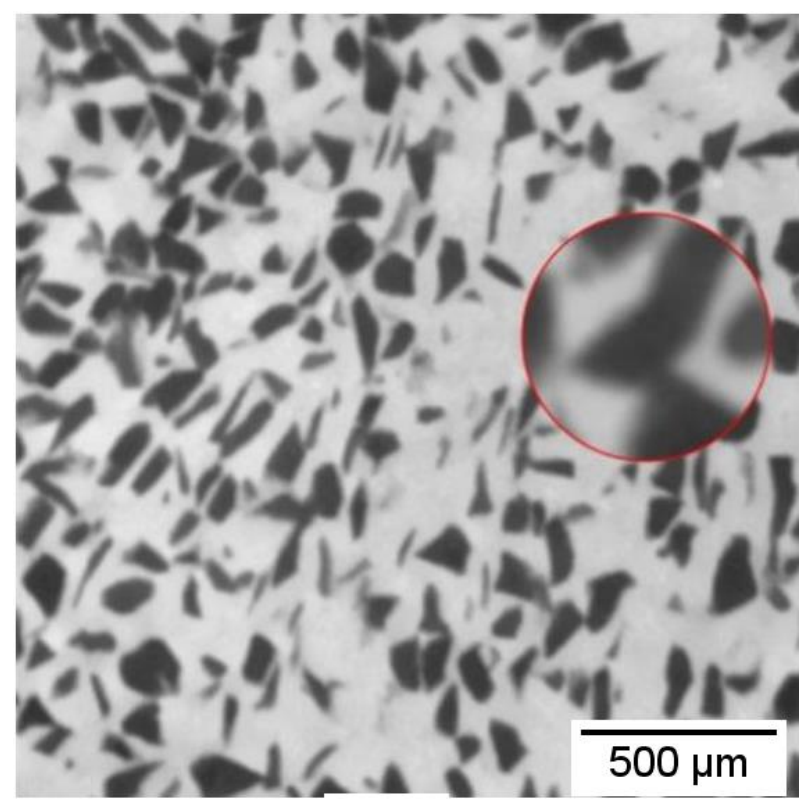

a)

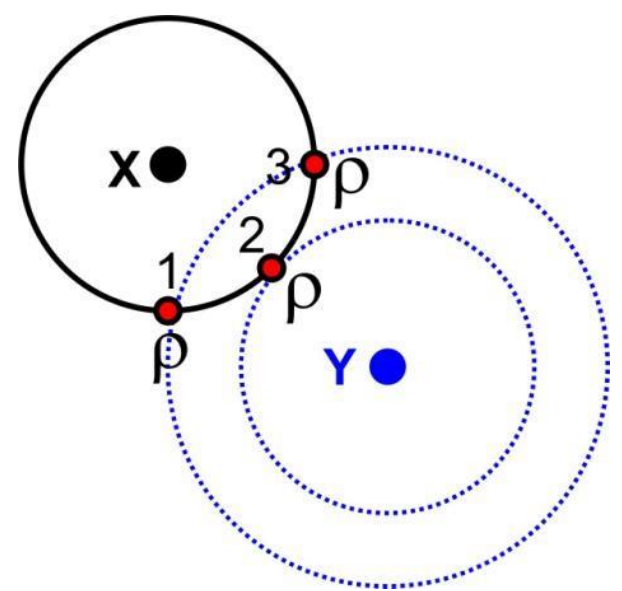

Fig. 3. Homogeneity follows from the isotropy around two points.

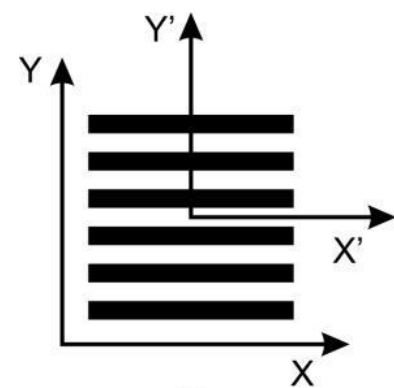

a

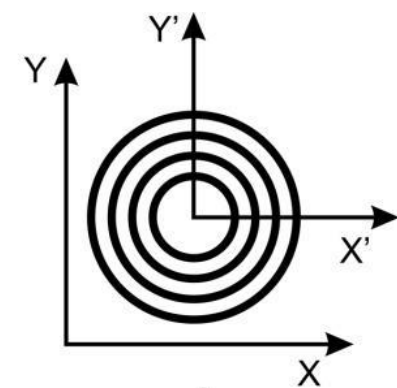

b
Fig. 4. The space in a) is homogeneous but not isotropic in both coordinate systems. In b) the space is isotropic for $X^{\prime} Y^{\prime}$ coordinate; not isotropic for $X Y$ coordinate system.

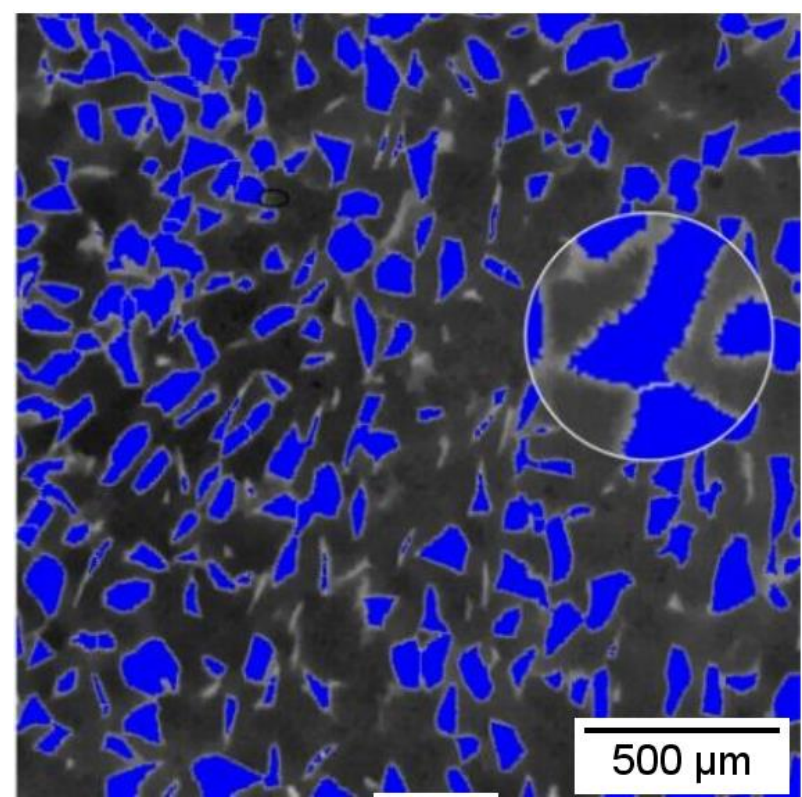

b)

Fig. 5. a) Real tomography image of SiC particles; b) binary mask of negative image. Inside the circles are enlarged fragments of grains with a white separation line 
Fig. 5 presents a tomography image, as well as its negative with an overlaid binary mask. The circles include zoomed-in areas with a visible separation of two objects. Sequences of binary maps were analyzed with 3D Slicer (https://www.slicer.org) and Fiji (https://fiji.sc), with our own procedures written in $\mathrm{C}++$. The $\mathrm{V}_{\mathrm{i}}$ volume of particles was determined, as well as the coordinates of their centers of mass $\left\langle x_{i}\left|y_{i}\right| z_{i}\right\rangle$; relative to the center of the sample and the external coordinate system. The coordinates of a center of mass were analyzed, in a coordinate system bound to the center of the sample, as well as the moments of inertia relative to an external coordinate system. The volume fraction of $\mathrm{SiC}$ phase was determined from the equation:

$$
V_{\text {SiC }}(\%)=\frac{\sum_{i} V_{i}(\text { SiC })}{V(\text { Specimen })} \times 100 \%
$$

The coordinates of the centers of mass:

$$
\begin{gathered}
m_{0 x(y, z)}=\frac{\sum_{i} m_{i}\left\langle x_{i}\left|y_{i}\right| z_{i}\right\rangle}{\sum_{i} m_{i}}=\frac{\sum_{i} \rho V_{i}\left\langle x_{i}\left|y_{i}\right| z_{i}\right\rangle}{\sum_{i} \rho V_{i}} \\
=\frac{\sum_{i} V_{i}\left\langle x_{i}\left|y_{i}\right| z_{i}\right\rangle}{\sum_{i} V_{i}}
\end{gathered}
$$

Moments of inertia were determined from the equation:

$$
\begin{aligned}
& I_{x}=\sum_{i}\left(\rho V_{i} \times x_{i}^{2}\right) ; \\
& I_{y}=\sum_{i}\left(\rho V_{i} \times y_{i}^{2}\right) ; \\
& I_{z}=\sum_{i}\left(\rho V_{i} \times z_{i}^{2}\right) ;
\end{aligned}
$$

For the representation of data, the quotient of moments was used:

$$
M_{x / y}=\frac{I_{x}}{I_{y}}=\frac{\sum_{i}\left(\rho V_{i} \times x_{i}^{2}\right)}{\sum_{i}\left(\rho V_{i} \times y_{i}^{2}\right)}
$$

For analysis purpose, simplification and increase of sensitivity we assumed dark-phase ( $\mathrm{SiC}$ ) density unity and only dark-phase center of geometrical mass and geometrical moments of inertia were calculated ( $\mathrm{Cu}$ phase was intentionally omitted).

\section{RESULTS}

Measuring sets $S\left(V_{i} ; x_{i} ; y_{i} ; z_{i}\right)$, depending on the percentage share of the $\mathrm{SiC}$ reinforcing phase, had the following range of $\mathrm{SiC}$ particle count: from $7.0 \times 10^{3}$ for $\mathrm{Cu} / 10$ vol. $\% \mathrm{SiC}$ to $3.8 \times 10^{4}$ for a $\mathrm{Cu} / 40$ vol.\% $\mathrm{SiC}$ sample. 3D visualization of such large groups of variables, in particular the space occupied by $\mathrm{SiC}$ particles, is completely unintelligible. This is why they are graphically represented as values indicating layers with the volume of $=(X \times Y) \times \Delta Z=(2000 \mu m \times$ $2000 \mu \mathrm{m}) \times 42.5 \mu \mathrm{m}$, where $(X, Y)$ are the full dimensions of a sample, $\Delta Z$ is the thickness of a layer in the direction of the $\mathrm{Z}$ axis. The volume fraction changes of $\mathrm{SiC}$ phase along $\mathrm{Z}$ direction is presented in Fig. 6, and the numerical results are shown in Table 1.

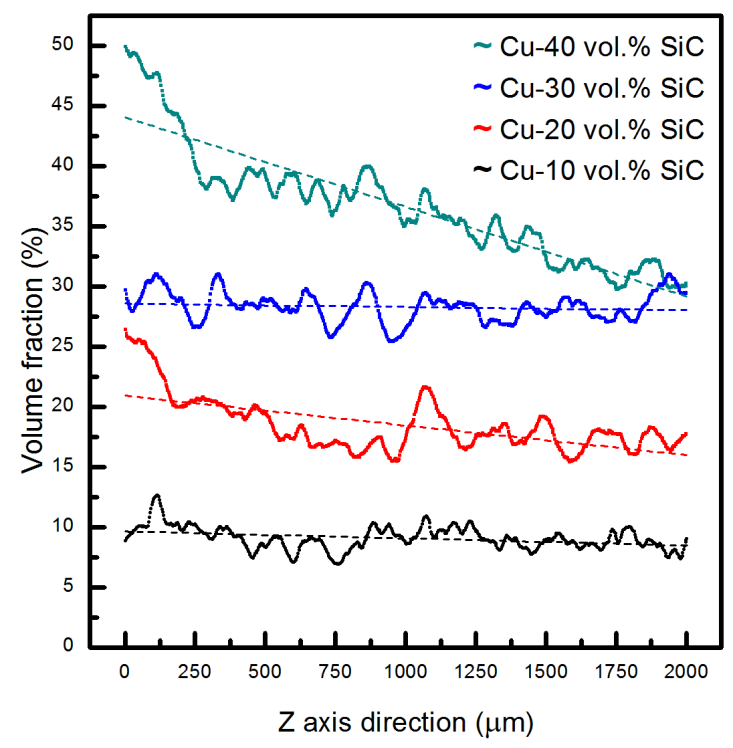

Fig. 6. SiC density results calculated for $42.5 \mu \mathrm{m}$ thick layers

The average volume fraction of the $\mathrm{SiC}$ reinforcing phase in all of the studied samples is lower than that that resulting from their preparation procedure. There are two significant sources of error resulting from the tomographic measurement. The first concerns overlaying binary masks over actual images, the second - tomography resolution. In Fig. 5b, in the negative image with overlaid binary masks, light spots can be clearly seen, as well as halos around particles that are not included in the dark blue masks. These areas are on the detection sensitivity threshold of the shades of grey related to the inside of $\mathrm{SiC}$ particles. The detection scale ranges from 0 for black to 255 for white. On the sensitivity threshold a change of the detection threshold by one step of the grayscale $\left(\frac{1}{256}\right)$ resulted in a change of the value of $\mathrm{SiC}$ particle volume by $\pm 0.9 \% \mathrm{~V}$. Lower resolution of tomography, compared to optical microscopy, resulted in the lack of the smallest particle group in the tomographic spectrum, with the volume around $0.2 \% \mathrm{~V}$. Consequently, the total error of the method was determined at the level of $\Delta V= \pm 1.1 \%$. 
The remaining error may be connected to the preparation procedures of $\mathrm{Cu} / \mathrm{SiC}$ composites. The character of errors related to the determination of $\mathrm{SiC}$ particle coordinates was the result of the algorithm separating the connected particles. It was determined that the best particle separation algorithm would be the one for which volumetric spectra of particles would be similar. It was assumed that the lowest separation error concerned the composite with the lowest phase share 10 vol.\% SiC. Out of the various tested algorithms, similar volume distributions of SiC particles (Fig. 7) for all four samples were obtained basing on the Integrating Concave Points Clustering and Random Walker Algorithm (He Y. et al., 2014). In absolute values, the error in values of particle coordinates was not determined. Error analysis of the measurement of the volume share of the SiC phase, as well as selecting the algorithm of particle separation was conducted for the composite layers with the following dimensions $2000 \times 2000 \times 200 \mu \mathrm{m}^{3}$.

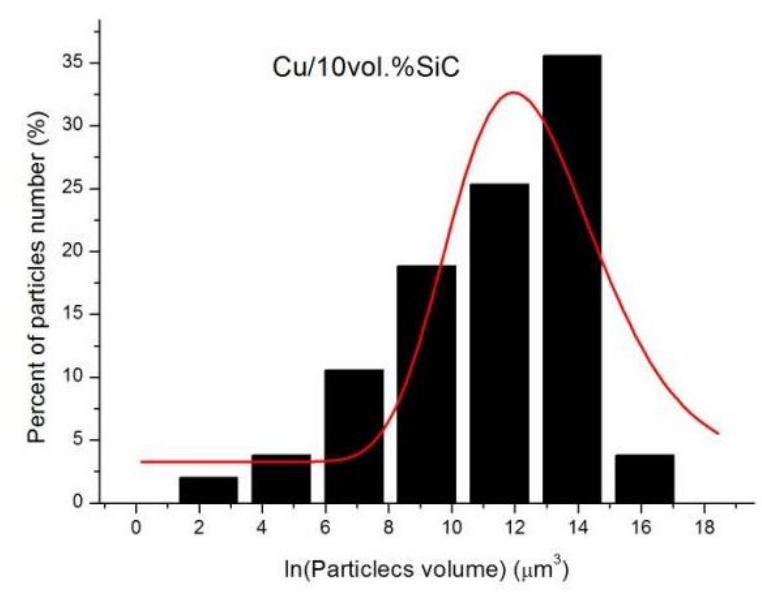

Fig. 7. Distribution of the volume of SiC particles.
Fig. 8 presents the distribution of coordinates of the centers of mass of $\mathrm{SiC}$ particles in the layers of the studied samples. The largest diffusion of coordinates is found in the composite with the lowest, 10vol.\% volume fraction of the $\mathrm{SiC}$ phase. For the isotropic material, the coordinates of the centers of mass should have the values of $x_{c}=y_{c}=z_{c}=0$.

The $\mathrm{Cu} / 30$ vol.\% SiC composite was identified as the most isotropic material - Table 1. It can be also found that the isotropy of the material increases with the increase of the volume fraction of the reinforcing phase.. In the $\mathrm{Cu} / 40$ vol.\%SiC material, the differences in the coordinates of the centers of mass, compared to the $\mathrm{Cu} / 30$ vol.\% SiC composite, are small but further research reveals significant changes of $\mathrm{SiC}$ particles along Z-axis dependence. They may result from a small, linear gradient of a particle mass distribution, presented in Fig. 6, as the inclination of a straight line that approximates the experimental data.

Theoretically, moments of inertia of masses, measured in an external coordinate system (Fig. 9) related to the uniform samples, should be identical therefore, their quotients should be identical. In order to compare homogeneity parameters of the analyzed samples the average value and standard deviation of moment quotient was calculated and compared in Table 1.

Table 1. Average density of SiC, coordinates of mass center and momentum of inertia determined from $3 D$ reconstruction of $\mathrm{Cu} / \mathrm{SiC}$ composite materials.

\begin{tabular}{|c|c|c|c|c|}
\hline Result & 10vol.\%SiC & 20vol.\%SiC & 30vol.\%SiC & $40 \mathrm{vol} . \% \mathrm{SiC}$ \\
\hline $\begin{array}{l}\text { Volume fraction of } \mathrm{SiC} \text {, } \\
\mathrm{V}_{\mathrm{V}}(\%)\end{array}$ & 9.07 & 18.64 & 28.31 & 36.62 \\
\hline $\begin{array}{l}\text { Relative coordinates of } \\
\text { mass centers } \\
\left(\begin{array}{c}x_{c} \mu m \pm s t d . \text { err. } \mu m \\
y_{c} \mu m \pm s t d . e r r . \mu m \\
z_{c} \mu m \text { Łslope } \frac{\%}{\mu m} \times 10^{-4}\end{array}\right)\end{array}$ & $\left(\begin{array}{c}69.7 \pm 63.7 \\
15.9 \pm 64.2 \\
-18.6 x-5.84\end{array}\right)$ & $\left(\begin{array}{c}77.3 \pm 41.5 \\
-11.6 \pm 37.5 \\
-321.1 \Varangle-24.6\end{array}\right)$ & $\left(\begin{array}{l}-55.4 \pm 25.7 \\
-60.1 \pm 29.7 \\
-8.8 \Delta-2.76\end{array}\right)$ & $\left(\begin{array}{c}4.3 \pm 29.6 \\
42.3 \pm 40.3 \\
-292.2 \not-74.5\end{array}\right)$ \\
\hline $\begin{array}{l}\text { Avg. inertia moment } \\
\text { quotient } \\
\qquad M_{x / y} \pm \text { std.err. }\end{array}$ & $1.38 \pm 0.23$ & $1.15 \pm 0.10$ & $1.10 \pm 0.03$ & $1.09 \pm 0.04$ \\
\hline
\end{tabular}




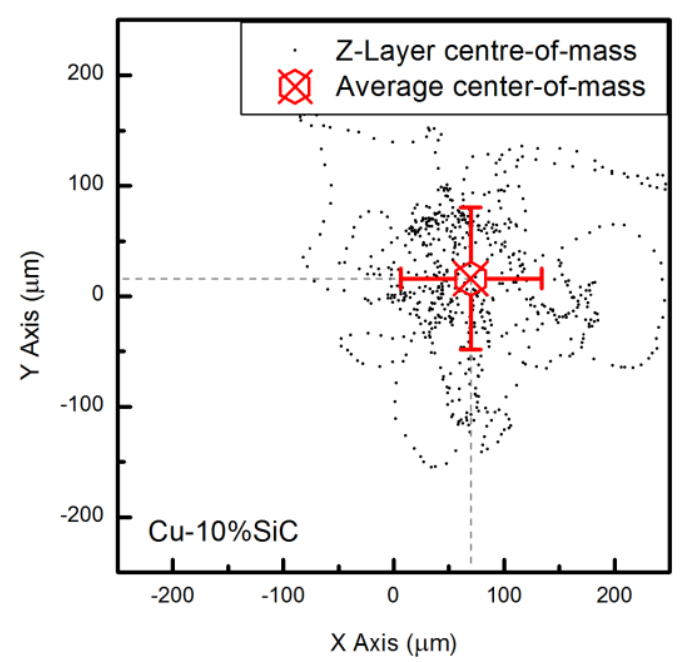

a)

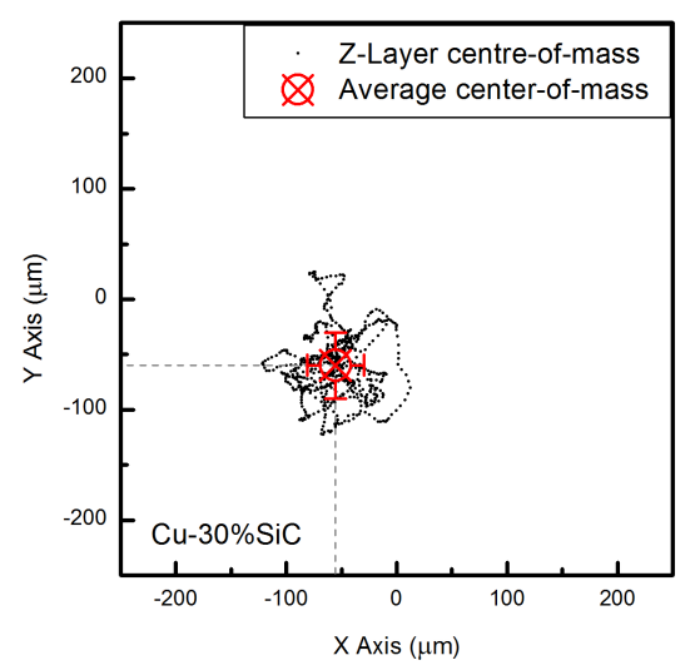

c)

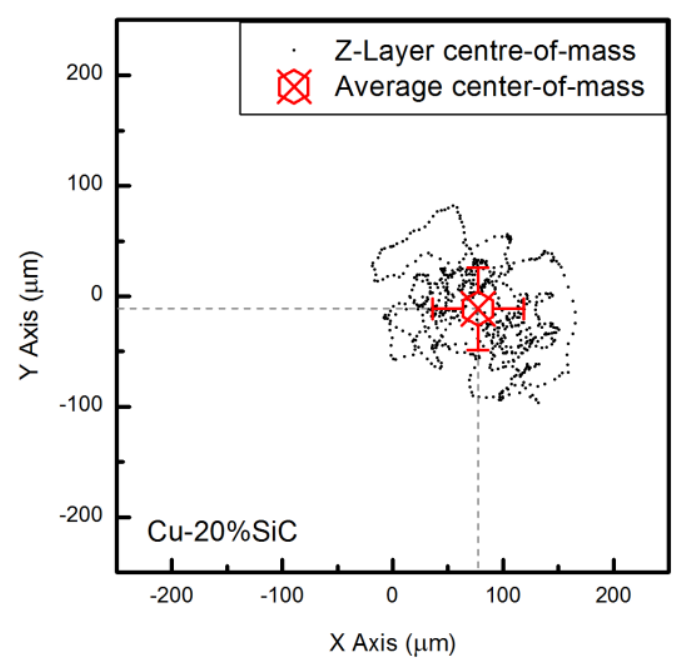

b)

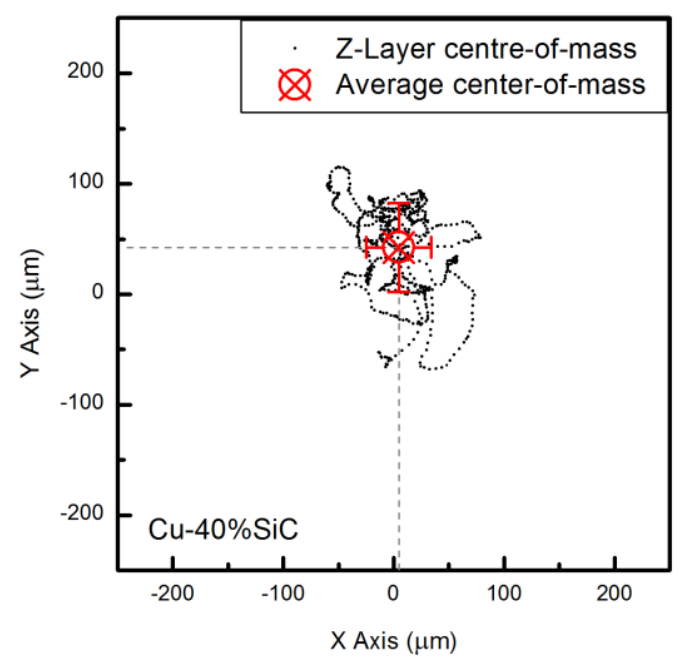

d)

Fig. 8. Distribution of mass centers coordinates in layers cutting in the direction of the $Z$ axis. Samples a) Cu/10vol.\%SiC; b) Cu/20vol.\%SiC; c) Cu/30vol.\%SiC; d) Cu/40vol.\%SiC.

Summing up the numerical results of research include in Table 1, it must be pointed out that the values of the volume fraction of the $\mathrm{SiC}$ phase $V_{S i C}(\%)$, within the margin of error $\Delta V= \pm 1.1 \% V$, are consistent with the conditions of the experiment. The differences in the determined coordinates of the centers of mass $\left(x_{c} ; y_{c} ; z_{c}\right)$ for the $\mathrm{Cu} / 10 \mathrm{vol} . \% \mathrm{SiC}$ and $\mathrm{Cu} / 20 \mathrm{vol} \% \mathrm{SiC}$ samples are significantly larger than in other two cases. Therefore, it should be assumed that within four studied samples, only $\mathrm{Cu} / 30 \mathrm{vol} . \% \mathrm{SiC}$ is isotropic and uniform. 


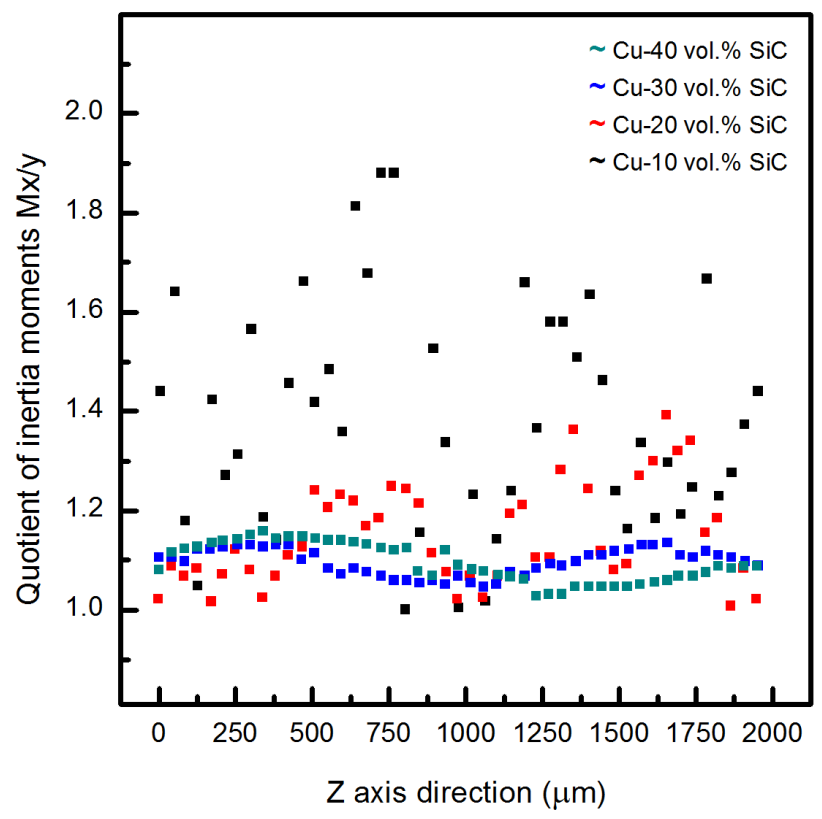

Fig. 9. Distribution of inertia moments quotients in layers cutting in the direction of the $Z$ axis.

\section{SUMMARY AND CONCLUSIONS}

Microtomography methods are undoubtedly a powerful tool in material research. At the same time, their use in quantitative structural analysis is a technically complicated process, mainly due to the separation of 3D-connected particles of shapes other than spherical, in various orientations. Ultimately, quantitative analysis of studied $\mathrm{Cu} / \mathrm{SiC}$ structures was conducted in the looped procedure system: separation of flat images, 3D reconstruction, calculation of particle volume, analysis of distributions of $\mathrm{SiC}$ particle volumes and their number. The results obtained by extensive analysis shown a general trend where increasing volume fraction of $\mathrm{SiC}$ resulted in higher isotropy an homogeneity of $\mathrm{SiC} / \mathrm{Cu}$ composites. The results are logically consistent with the thesis that two materials with similar particle shapes and sizes may be well mixed in a gravitational field, even with differing specific weights. In addition, an increase in the density of the reinforcing phase, provided the components are uniformly mixed, must increase its isotropy, within the identical - with respect to size and shape - spaces of composite formation. The mechanical and thermal loading applied during materials fabrication had a lesser impact on the translational or rotational motion of powder particles as their volume fraction in the material raised. Gravitational segregation along $\mathrm{Z}$ axis is also visible and was not significant only in the $30 \mathrm{vol} . \% \mathrm{SiC}$ composition.

\section{ACKNOWLEDGEMENT}

The studies have been carried out as a part of the project entitled "The correlation between interface morphology and heat transfer in $\mathrm{Cu}-\mathrm{SiC}$ composites in function of the form of reinforcement material" financed by the National Science Center within the framework of OPUS Programme (contract ref. no.: 2014/13/B/ST8/04320)

\section{REFERENCES}

Barmouz M., Araee A. (2014) Effect of SiC particles dispersion on the grain size and mechanical properties of $\mathrm{Cu} / \mathrm{SiC}$ metal matrix nanocomposites produced via MFSP", J Nano Res 26:53-8.

Besharati M.K., Taherishargh G.M. (2011) Investigation of mechanical properties of $\mathrm{Cu} / \mathrm{SiC}$ composite fabricated by FSP: effect of $\mathrm{SiC}$ particles' size and volume fraction. Mater Sci Eng: A 528(3):1740-9.

Campbell F.C. (2010) Introduction to Composite Materials Structural Composite Materials. ASM International® http://www.asminternational.org

Chmielewski M., Pietrzak K., Strojny-Nędza A., Jarząbek D., Nosewicz S., (2017) Investigations of interface properties in copper-silicon carbide composites. Arch Metall Mater 62(2B):1315-8.

Chmielewski M., Pietrzak K., Teodorczyk M., Nosewicz S., Jarzabek D., Zybała R., Bazarnik P., Lewandowska M., Strojny-Nedza A. (2017) Effect of metallic coating on the properties of coppersilicon carbide composites. Appl Surf Sci 421A:15969.

DeHoff R.T., Rhines F.N. (1961) Determination of the number of particles per unit volume from measurements made on random plane section: the general cylinder and the ellipsoid. Trans AIME 221:975-82.

Gan K., Gu M. (2008) The compressibility of $\mathrm{Cu} / \mathrm{SiCp}$ powder prepared by high-energy ball milling. J Mater Process Tech 199 (1-3):173-7.

Gawdzińska K., Wojnar L., Maliński M., Chrapoński J. (2010) Structure homogeneity as a parameter for evaluation of composite casting quality. Archives of Foundry Engineering 10(3):187-92. 
Głowacz E., Czarski A. (2008) Scheil-SchwartzSaltykov method in the matrix depiction. Inżynieria Materiałowa 29(4):418-20.

He Y., Meng Y., Gong H., Chen S., Zhang B., Ding W., Luo Q., Li A. (2014) An automated threedimensional detection and segmentation method for touching cells by integrating concave points clustering and random walker algorithm., PLOS One 9(8).

Iguchi M., Suehirto T., Watanabe Y. (1982) Composite materials reinforced with polyoxymethylene wiskers. J Mater Sci 17:1632-8.

Jarzabek D., Chmielewski M., Dulnik J., StrojnyNedza A. (2016) The influence of the particle size on the adhesion between ceramic particles and metal matrix in MMC composites. J Mater Eng Perform 25(8):3139-45.

Kimoto T., Cooper J. A. (2014) Fundamentals of Silicon Carbide Technology: Growth, Characterization, Devices, and Applications , Major Physical Properties of Common SiC Polytypes, First Edition Published by John Wiley \& Sons Singapore Pte Ltd. 7.

Maire E., Withers P. J. (2014) Quantitative X-ray tomography. Int Mater Rev. 59(1):1-43, 23.

Pietrzak K., Sobczak N., Chmielewski M., Homa M., Gazda A., Zybała R., Strojny-Nędza A. (2016) Effects of carbon allotropic forms on microstructure and thermal properties of $\mathrm{Cu}-\mathrm{C}$ composites produced by SPS. J Mater Eng Perform 25(8):307783.

Schubert Th., Brendel A., Schmid K., Koeck Th., Ciupiński Ł., Zieliński W., Weißgärber T., Kieback B. (2007) Interfacial design of $\mathrm{Cu} / \mathrm{SiC}$ composites prepared by powder metallurgy for heat sink applications. Compos Part A-Appl S. 38(12):2398403.

Singh H., Kumar L., Alam S. N. (2015) Development of $\mathrm{Cu}$ Reinforced SiC Particulate Composites. $4^{\text {th }}$
National Conference on Processing and Characterization of Materials IOP Conf. Series: Mater Sci Eng. 75.

Srinivasan C., Karunanithi M. (2015) Fabrication of surface level $\mathrm{Cu} / \mathrm{SiCp}$ nanocomposites by friction stir processing route. J Nanotechnol. Article ID 612617:1 -10 13 .

Underwood E.E. (1970) Quantitative Stereology, Addison-Wesley; Massachusetts, U.S.A.

Weber L., Tavangar R. (2007) On the influence of active element content on the thermal conductivity and thermal expansion of $\mathrm{Cu}-\mathrm{X}(\mathrm{X}=\mathrm{Cr}, \mathrm{B})$ diamond composites. Scripta Mater 57:988-91.

Wejrzanowski T., Spychalski W.L., Rożniatowski K., Kurzydłowski K.J., (2008), Image based analysis of complex microstructures of engineering materials. Int J Appl Math Comp. 18(1):33-9.

Wejrzanowski T., Lewandowska M., Kurzydłowski K.J., (2010), Stereology of nanomaterials., Image Anal Stereol 29:1-12.

Xu Y.H., Pitot H.C. (2003) An improved stereologic method for three-dimensional estimation of particle size distribution from observations in two dimensions and its application. Comput Meth Prog Bio 72(1):1-20.

Yoshida K., Morigami H. (2004) Thermal properties of diamond/copper composite material. Microelectron Reliab 44:303-8.

Zaman M., Bukhari S.N.S., Ir M., Brabazon D., Hashmi M.S.J. (2012) Evaluation on metal matrix composite of $\mathrm{CuSiC}$ as candidate for thermal management materials in electronics packaging. The 2nd International Malaysia-Ireland Joint Symposium on Engineering, Science and Business 2012.

Zhan Y., Zhang G. (2003) The effect of interfacial modifying on the mechanical and wear properties of $\mathrm{SiC} \mathrm{p} / \mathrm{Cu}$ composites. Mater Lett. 57:4583. 